\title{
Assessment of the Using Patterns of Pesticides and Its Impact on Farmers Health in the Jhenidah District of Bangladesh
}

\author{
Most. Nasima Akhter ${ }^{1}$, Tapos Kumar Chakraborty ${ }^{2, ~ *}$, Prianka Ghosh ${ }^{2}$, Sayka Jahan ${ }^{2}$, \\ Gopal Chandra Ghosh ${ }^{2}$, Sheikh Abir Hossain ${ }^{2}$ \\ ${ }^{1}$ Department of Sociology, Baliadanga Khanpur College, Monirampur, Jessore, Bangladesh \\ ${ }^{2}$ Department of Environmental Science and Technology, Jessore University of Science and Technology, Jessore, Bangladesh
}

Email address:

juie69nasima@gmail.com (M. N. Akhter), taposchakraborty@rocketmail.com (T. K. Chakraborty), priankaghoshest@yahoo.com (P. Ghosh), saykaes@yahoo.com (S. Jahan), gopales8@hotmail.com (G. C. Ghosh), abirhasan33571@gmail.com (S. A. Hossain)

*Corresponding author

\section{To cite this article:}

Most. Nasima Akhter, Tapos Kumar Chakraborty, Prianka Ghosh, Sayka Jahan, Gopal Chandra Ghosh, Sheikh Abir Hossain. Assessment of the Using Patterns of Pesticides and Its Impact on Farmers Health in the Jhenidah District of Bangladesh. American Journal of Environmental Protection. Vol. 5, No. 5, 2016, pp. 139-144. doi: 10.11648/j.ajep.20160505.16

Received: August 28, 2016; Accepted: September 5, 2016; Published: September 22, 2016

\begin{abstract}
Unreasonable utilization of pesticides is progressively debilitating our biological community, well-being and environment. The main objectives of these studies were to examine the pesticide using pattern and its impact on farmer's health. Kaligonj and Jhenaidah sadar upazila of Jhenaidah districts were selected as a study area, where agriculture is the main sources of livelihood. Data were collected from randomly selected 80 farmers through a defined questionnaire. Study finding indicates that most of the farmers used insecticide (80\%) in their agricultural fields and about $(75 \%)$ farmers were could not read the level of the pesticides packet/bottle as a result they applied in a high dose. About seventy-seven percentage (77\%) farmers used hand derived sprayer machines for pesticide application and during that time $80 \%$ farmers were not taking any types of protective measures. Gastro- intestinal diseases (84\%), eye diseases (64\%), skin diseases $(60 \%)$ and urine and sexual diseases $(54 \%)$ were the most common diseases in the study area. Farmers who were engaged in agricultural practices during 15-19 years they were suffering most from various types of health problem. Intensive awareness training of farmers on safety measures regarding the application of pesticides and its rational use is necessary to avoid potential health hazards.
\end{abstract}

Keywords: Pesticides, Using Patterns, Health Impacts, Farmers, Bangladesh

\section{Introduction}

Pesticides are used in agriculture in order to control pests and disease attacks of plants for improving productivity. It has different types such as molluscides, rodenticides, fungicides, herbicides, insecticides and plant regulators [1]. Though it is beneficial for crop production, but it has a great negative impact on environment and health [2, 3, 4]. During 1970s negligible amount of pesticide were used in Bangladesh but at present time Pesticide use levels have increased from 2,200 metric tons in 1980-82 to 6,500 metric tons in 1992-94 and modern rice cultivation increased from 20.3 percent of total rice area to 49.0 percent during the same period [5].

Mostly Bangladeshi farmer is used insecticides and a little amount of herbicides, fungicides, acaricides and rodenticides in their agricultural field in the forms of granules, liquid and powder [6]. In modern aged most of the farmer are gradually depends on chemical pesticide including toxic chemicals than traditional method and IPM [7, 8]. In a developing country like Bangladesh, more than $90 \%$ of farmers used pesticide without knowing its actual requirements and they used pesticide unnecessarily, indiscriminately and excessively at high concentration and more frequent due to their ignorance and unconsciousness about the use, for example150 sprays in a crop season in brinjal in Bangladesh [9, 10].

In Bangladesh many farmers spray pesticides without 
taking any safety measures (wearing masks, gloves and other proper clothes) in the crop field that are highly vulnerable to suffer from various diseases because they absorb the toxic item unaware in different ways, including inhalation, dermal contact etc. [6]. Even farmers also clean the spraying pipe through their mouth [11].Over $87 \%$ farmers report to openly admit of using little or no protective measures while applying pesticides and $92 \%$ of them do not take any protective measures during use, storage, transport etc. Pesticides can enter into human body during and after application through its different parts. The rate of dermal absorption of pesticide residues varies with the parts of body such as scalp (3.7\%), forehead (4.2\%), ear canal (5.4\%), abdomen (2.1\%), forearm $(1.0 \%)$, palm $(1.3 \%)$, genital area $(11.8 \%)$ and ball of foot $(1.6 \%)$. For these reason they are suffer from various types of health problems such as abdominal pain, dizziness, headaches, nausea, vomiting, as well as skin and eye problems [12]. The World Health Organization (WHO) and the United Nations Environment Program estimate nearly 4.0 million people suffer from severe pesticide poisoning and its rate is 2-3 per minute, with approximately 20,000 workers dying from exposure every year, the majority in developing countries $[13,14,15]$. The main objectives of these were to examine the pesticide using pattern and its impact on farmer's health.

\section{Methodology}

\subsection{Research Approach}

Survey method is adopted to determine the pesticide using pattern and the impact of pesticide on farmer's health based on proposed objectives.

\subsection{Study Area}

Kaligonj and Jhenidah sadar upazill ${ }^{1}$ in Jhenidah district ${ }^{2}$ were selected as study area. Detail informations about study area are presented in table 1.

Table 1. Description of selected study area [16].

\begin{tabular}{|c|c|c|}
\hline Selected criteria & Kaligonj Upazilla & Jhenidah Sadar Upazilla \\
\hline \multirow[t]{2}{*}{ Population } & Total $=252443$ & Total $=394152$ \\
\hline & $\begin{array}{l}\text { Male }=130716, \\
\text { Female }=121727\end{array}$ & $\begin{array}{l}\text { Male }=204256 \\
\text { Female }=189896\end{array}$ \\
\hline Literacy rate & $\begin{array}{l}\text { Average literacy }=46.2 \% \\
\text { Male }=51.1 \% \\
\text { Female }=51 \%\end{array}$ & $\begin{array}{l}\text { Average literacy }=47.4 \% \\
\text { Male }=52.3 \% \\
\text { Female }=42.1 \%\end{array}$ \\
\hline $\begin{array}{l}\text { Main Sources of } \\
\text { income }\end{array}$ & Agriculture $=64.40 \%$ & Agriculture $=60.12 \%$ \\
\hline
\end{tabular}

\subsection{Sampling Technique and Sample Size}

The technique of stratified random sampling was used to obtain cross-sectional data for these studies. The farms were

1 Upazilas are the second lowest tier of the administrative unit of local government in Bangladesh.

2 Districts are the first tier of the administrative unit of local government in Bangladesh. selected randomly from within the selected areas. As a result, a total of 80 farmers were selected randomly (40 from each upazilla).

\subsection{Data Collection Technique}

Face-to-face key informant interviews with farmers were conducted for data collection. On the other hand discussions also conducted with the consultants and specialist doctors of skin, eye, medicine, urology, cardiology, neurology and cancer in order to understanding the potential effects of pesticide on farmer's health. Date of data collection was $15^{\text {th }}$ March'2016 to 30 ${ }^{\text {th }}$ March'2016.

\subsection{Study Tool}

Survey questionnaires containing both structured and nonstructured questions about duration of cultivation, types of pesticides use, pre-cautionary measures practice, health symptoms of the farmers due to pesticide exposure etc.

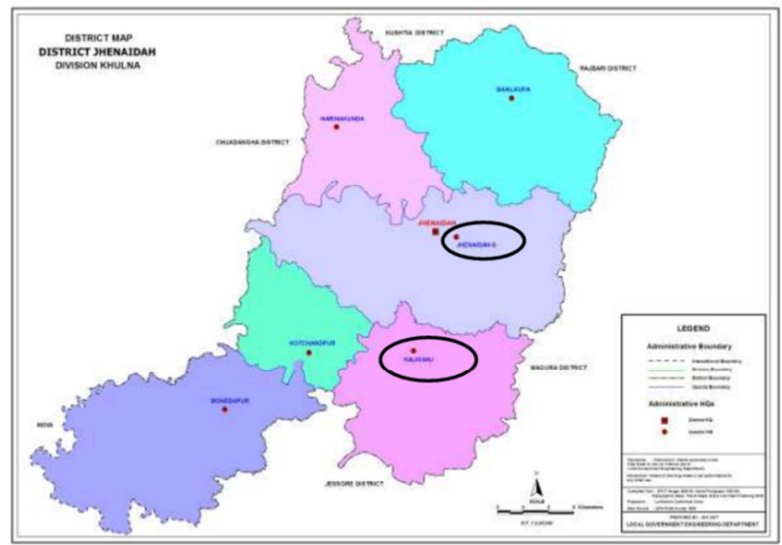

Figure 1. Map of selected study area (Kaligonj upazilla and Jhenidah sadar upazilla in Jhenidah district of Bangladesh).

\subsection{Data Analysis}

All data were coded, entered, and then analyzed using the Statistical Package for Social Sciences (SPSS) program, version 16 and MS excel 2010. Descriptive results were expressed as numbers, and percentages for categorical variables.

\section{Results and Discussion}

\subsection{Demographic Profile of Farmers}

Table 2 summarizes the characteristics of farmers interviewed and showed that all of the farmers were male (100\%). Also, nearly 36\% farmers were within 31-40 year old, $31 \%$ farmer were $41-50$ year old, $19 \%$ farmer were 20 30 year old, $11 \%$ farmer were 51-60 and only 3\% farmer were over 60 year old. Data shown in Table 1 also indicated education status where $42 \%$ of the farmers had attained primary level, 26\% secondary level, and $16 \%$ higher secondary, $10 \%$ illiterate and only $6 \%$ farmer were graduate. This is an indication that farming is not attractive to tertiary 
education graduates. Majority percentage $(45 \%)$ of farmer family income within $3000 \mathrm{TK} /$ month, $30 \%$ family income 3001-5000 TK/month, $20 \%$ family income 5001-10000
TK/month and 5\% family income above $10000 \mathrm{TK} / \mathrm{month}$ (Table 2).

Table 2. Demographic profile of farmers in the study area.

\begin{tabular}{|c|c|c|c|}
\hline Selected Characteristics & Categories & Number $(n=80)$ & Percentage (\%) \\
\hline Gender & Male & 80 & 100 \\
\hline \multirow{5}{*}{ Age (years) } & $20-30$ & 15 & 19 \\
\hline & $31-40$ & 29 & 36 \\
\hline & $41-50$ & 25 & 31 \\
\hline & $51-60$ & 9 & 11 \\
\hline & 60 above & 2 & 3 \\
\hline \multirow{4}{*}{ Educational Level } & Illiterate & 8 & 10 \\
\hline & Secondary & 21 & 26 \\
\hline & Higher secondary & 13 & 16 \\
\hline & Graduation & 5 & 6 \\
\hline \multirow{4}{*}{ Monthly Income (Bangladesh Taka) } & less 3000 TK per month & 36 & 45 \\
\hline & 3001-5000 TK per month & 24 & 30 \\
\hline & 5001-10000 TK per month & 16 & 20 \\
\hline & Above 10000 TK per month & 4 & 5 \\
\hline
\end{tabular}

\subsection{Pesticide Using Pattern in the Study Area}

\subsubsection{Types of Pesticide Applied by Farmers}

Many economically important vegetable crops are cultivated in the study area. Among them brinjal (Solanum melongena L.), chilli (Capsicum annum L.), long bean (Vigna unguiculata L.) and okra (Abelmoschus esculentus L.) are the major cultivated vegetable crops. In the study area pesticide users reveals that all farmers use insecticides with the high percentage $(80 \%)$ compared to others pesticides. The order of dominance used in the study area are insecticides > fungicides $>$ herbicides while such order by class is organophosphates $>$ synthetic pyrethroids $>$ carbamates. The farmers of this area use fungicides and herbicides with the percentages of $8 \%$ and $12 \%$ (Table 4 ). The vegetable farmers use more than 10 type's pesticides to control pest infestation and minimize crop losses. It was also found that, pesticides were applied without adequate knowledge of pest ecology, economic injury levels and type of pesticides to control specific insect pest, their quantities and method of application, pre harvest interval and protective measures. Farmers want to solve pest problems for this purpose they spray more frequently and using different types of pesticides (Table 3).

Table 3. Product name and chemical group of pesticides used in the study area.

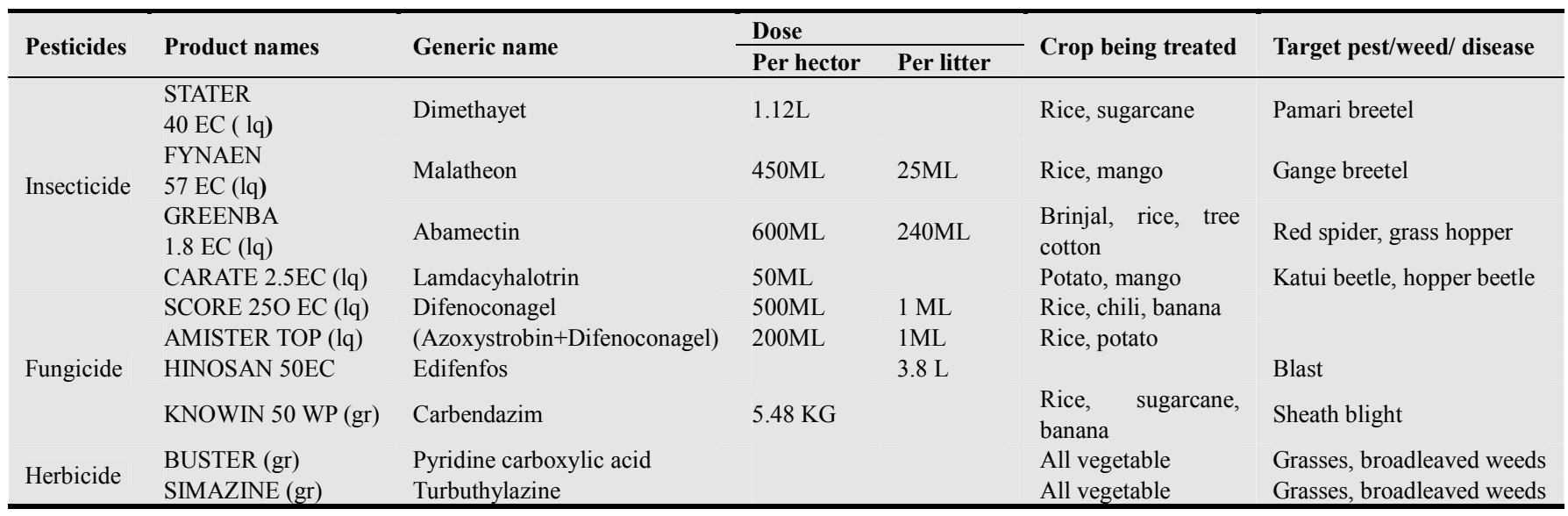

$(\mathrm{Gr}=$ granular, $\mathrm{lq}=$ liquid; multiple answers considered $)$

\subsubsection{Level of Pesticide Used}

Only about $20 \%$ of applicators can able to read the level which are written on Bottles or Packets while 75\% can't read the level of pesticide Bottles or Packets (Table 4). They are depend on pesticide sellers opinion. Generally, pesticide sellers are not properly trained up, they learn about pesticide from the representative of the company orally. Moreover, farmers complained that block supervisors or agricultural officials are rarely seen and do not provides proper suggestions about pesticides using dose.

\subsubsection{Methods of Pesticide Application}

In the study area majority of farmers $(77 \%)$ reported that they applied pesticide with hand drive spray machine. Few farmers about $14 \%$ used pesticides through injection process. 
About 9\% farmers used both spraying machine and injection during pesticides application (Table 4). The hand drive spray machine are available in our country and it's comparatively cheap than others modern machine but it has a demerit, where pesticide are not apply properly.

\subsubsection{Adoption of Protective Measures}

The study area farmers are unaware about protective coverings at the time of handling, transporting, storing and spraying. Although 15\% users take partial safety measures (wearing shirt and trousers, gloves, mask etc.) during pesticides application. Around $80 \%$ don't wear protective measure (hand gloves, mask, goggles, full pant or shirt etc.) before going to spray and cleanse hands and face with soap after finishing. About 5\% take bath after pesticide use for getting rid of odor (Table 4). This area farmer said that pesticide spraying is a regular work for them so it is not necessary to take any protective measure and they also said that they are habituated with this activity.

\subsubsection{Storage and Disposal of Pesticide Packets or Battles}

About $80 \%$ of the farmers throw the battles or packets in their agricultural field after used and 20\% farmers return pesticide battles in their home for further purpose (Table 4). Thy have no concern about this things after use as a result they thrown it here and there. But it has a negative impact on health and environment.

\subsubsection{Smoking, Drinking and Food Consuming During Pesticide Applications}

Majority percentages of respondents reported that they consume something during pesticides application in the fields. Among them the highest proportion of respondents said that they often smoke cigarette $80 \%$ and drink water $15 \%$ and $5 \%$ take rice or other food during the period of pesticide application which makes them more vulnerable in terms of user's health (Table 4).

Table 4. Pesticide use Patterns and precautionary measures taken by farmer.

\begin{tabular}{|c|c|}
\hline Variables & $\%$ of the respondent \\
\hline \multicolumn{2}{|l|}{ 1. Types of pesticides use } \\
\hline a) Insecticides & 80 \\
\hline b) Herbicides & 12 \\
\hline c) Fungicides & 8 \\
\hline \multicolumn{2}{|l|}{ 2. Level of pesticide used } \\
\hline a) Read the level of packet/battle & 20 \\
\hline c) Understand the level of pesticide & 5 \\
\hline \multicolumn{2}{|l|}{ 3. Methods of pesticide application } \\
\hline a) With hand derived sprayer machine & 77 \\
\hline b) Injection & 14 \\
\hline c) Both with sprayer machine and injection & 9 \\
\hline \multicolumn{2}{|c|}{ 4. Protective measures taken during and after using pesticide ${ }^{*}$} \\
\hline a) Partial safety measures & 15 \\
\hline c) Wash hand or taking bath after spraying & 5 \\
\hline \multicolumn{2}{|c|}{ 5. Storage and dispose of pesticide packet or battle ${ }^{*}$} \\
\hline a) Returned to the company or distributer & 0 \\
\hline b) Through it to the open field & 80 \\
\hline c) Burnt & 0 \\
\hline d) Carry in home & 20 \\
\hline \multicolumn{2}{|l|}{ 6. Smoking, drinking and consuming food ${ }^{*}$} \\
\hline a) Smoke cigarette & 80 \\
\hline b) Drink water & 15 \\
\hline c) Take rice others food & 5 \\
\hline
\end{tabular}

(*Multiple-answer considered).

\subsection{Impact of Pesticides on Farmers Health}

\subsubsection{Skin Diseases}

During the handling, transporting and processing pesticides can come into contact with and enter the body causing various types of skin diseases. Pesticide users in the study area are often exposed dermally; about $60 \%$ reported suffering from skin diseases including irritation and itching (Table 5). According to Kaligonj Upazila health officers, the number of patients with skin diseases is increasing day by day, among them most of the farming community.

\subsubsection{Eye Diseases}

The present study found that almost all of the farmers spray pesticides without wearing protective eye glasses. About $64 \%$ of total respondents reported having eye problems such as-itching, irritation, pain, cataract, and pupil problem and diminished eye sight, either temporarily or permanently (Table 5). It is shown that the farmers cultivating vegetables as well as using pesticides for a long time (15-19 years) have been suffering from eye diseases 
more severely. Sobuj (age 30), a vegetable farmer in Kaligonj upazila, said that "one day I sprayed pesticides in the vegetable field against wind direction and some droplet fell on my eyes which resulted in pupil problem (white spot) and suffering till today".

\subsubsection{Gastro-intestinal Diseases}

The survey study also found that $84 \%$ of applicators are suffering from gastro-intestinal diseases such as stomachache, digestion problems, and loss of appetite and vomiting during and after pesticide application (Table 5). Among these, appetite problem is found at a very high rate (78.33\%). About $16.75 \%$ found that they are suffering from digestion problem due to pesticide application. Salam (45) a farmer from Jenidah sadar upazilla, who has been using pesticide desperately for nearly 30 years explained: "now-adays I do not feel any appetite for food; even I think I can pass few days without taking any food. I strongly believe that this is the result of unsafe and indiscriminate process of applying pesticides".

\subsubsection{Urine and Sexual Diseases}

About $54 \%$ of pesticides users report suffering from various types of urine and sexual diseases such as kidney problems, reduction of urine control and less sexual urge. Although farmers interviewed felt shy to speak about such kind of problems, $29.4 \%$ confess that they have lost their sexual urge gradually after being introduced to pesticide application in the field (Table 5).

\subsubsection{Others Diseases}

Analyzed data also show that, almost all pesticides used by the farmers are of organophosphate chemical group that are found in different trade names and have been suffering at least one disease while some of them exhibited multi diseases categorized under short term diseases such as- physical weakness, dizziness, chest pain, uneasiness and long term diseases such as- breathing problem, excessive sweating and fatigue. Moreover, $46.6 \%$ report that the physical weakness and uneasiness is experienced during or after their applying pesticides even for a short period of time (Table 5).

Table 5. Impacts of pesticide on farmer's health in the study area.

\begin{tabular}{|c|c|c|c|c|c|c|}
\hline \multirow{2}{*}{ Disease patterns } & \multicolumn{6}{|c|}{$\%$ of respondent ( cultivation period in year) } \\
\hline & $<15$ year & 15-19 year & 20-24 year & 25-29 year & $>30$ year & Total \\
\hline 1. Skin diseases ${ }^{*}$ & & & & & & 60.0 \\
\hline a) Body itching & 8.5 & 9.3 & 6.5 & 2.0 & 8.4 & 34.7 \\
\hline b) Body irritation & 10.36 & 20.5 & 11.56 & 13.11 & 9.77 & 65.3 \\
\hline 2. Eye diseases ${ }^{*}$ & & & & & & 64.0 \\
\hline a) Eye pain & 3.73 & 4.15 & 0.0 & 1.34 & 1.34 & 10.46 \\
\hline c) Eye irritation & 2.31 & 5.36 & 4.95 & 1.32 & 2.63 & 16.57 \\
\hline d) Cataract & 4.0 & 5.23 & 0.0 & 3.95 & 7.26 & 20.44 \\
\hline b) Little vision & 4.63 & 9.89 & 17.84 & 6.57 & 9.11 & 48.04 \\
\hline 3.Gastro- intestinal disease ${ }^{*}$ & & & & & & 84.0 \\
\hline a) Digestion problem & 0.93 & 4.95 & 0.98 & 4.94 & 4.95 & 16.75 \\
\hline b) Loss of appetite & 15.76 & 26.57 & 13.5 & 6.81 & 15.69 & 78.33 \\
\hline c) Vomiting & 0.0 & 0.0 & 4.92 & 0.0 & 0.0 & 4.92 \\
\hline 4. Urine and sexual diseases ${ }^{*}$ & & & & & & 54.0 \\
\hline a) Kidney problem & 0.0 & 0.0 & 0.0 & 2.6 & 0.0 & 2.6 \\
\hline b) Urine control problem & 17.0 & 19.0 & 19.0 & 10.0 & 4.0 & 69.0 \\
\hline c) Reduction of sexual urge. & 3.0 & 13.0 & 5.4 & 3.0 & 5.0 & 29.4 \\
\hline 5. Other diseases ${ }^{*}$ & & & & & & \\
\hline a) Physical weakness & 10.2 & 9.8 & 7.3 & 7.8 & 11.5 & 46.6 \\
\hline b) Dizziness & 3.25 & 4.5 & 1.4 & 1.4 & 4.0 & 14.55 \\
\hline c) Breathing problem & 1.7 & 2.3 & 0.8 & 0.0 & 2.5 & 7.3 \\
\hline d) Uneasiness/trouble & 9.5 & 7.25 & 4.0 & 4.25 & 6.5 & 31.5 \\
\hline
\end{tabular}

(*Multiple-answer considered).

\section{Conclusions and Recommendations}

Jhenaidah districts are the major vegetable producing area in the southern part of Bangladesh. In the study area farmers used heavy dosages of pesticides with regular intervals in order to protect their vegetable crops. They are mostly used insecticides of organophosphate chemical group rather than other types of pesticides. Generally, they are not much aware of pesticide toxicity and never take any protective measures during the time of handling, carrying, mixing, storing or any other type of contact and disposal of pesticides. Most of the farmers use pesticides higher level than the recommended level because they use only chemical pest control method and they are not able to read the pesticides bottles/packets recommended level. On the other hands pesticides user is committed various types of activates such as smoking, drinking and consuming something during application which has a negative impacts on health. Gastro- intestinal diseases, eye diseases, skin diseases and urine and sexual diseases were the most common diseases in the study area. These studies also mention that higher level of sufferings was found of those farmers, who have been cultivating crops for 15-19 years. After completing this study it suggest that, farmers should take training on safety measures regarding the application of pesticides and its rational use and always wear protective clothing (masks, hand gloves, glasses, full shirt, full pant etc.) before pesticide application for reducing health impact. 


\section{References}

[1] I. J. Tekwa, O. Y. Ambali and B. H. Gabdo, "Economic analysis of farm hazards associated with the use of agrochemicals on agricultural farms", Australian Journal of Agricultural Engineering, 1(1), 2010, pp. 7-13.

[2] World Health Organization (WHO), "Guidelines for drinkingwater quality”, 2nd ed., Geneva, 1997.

[3] E. E. K. Clarke, L. S. Levy, A. Spurgeon and I. A. Clavert, "The problems associated with pesticide use by irrigation workers in Ghana", Occupational Medicine, 47(5), 1997, pp. 301-308.

[4] J. R. Krebs, J. D. Wilson, R. B. Bradbury and G. M. Siriwardena, "The second silent spring?", Nature, 400, 1999 pp. 611-612.

[5] S. Rahman and G. B. Thapa, "Environmental impact of technological change in Bangladesh agriculture: farmers' perception and empirical evidence", Outlook on Agriculture, 28, 1999, pp. 233-238.

[6] P. Gain, "Pesticide Doesn't Guarantee Increased Crop Yield", in Gain, P. et al. (Eds), Bangladesh Environment: Facing the 21st Century, Society for Environment and Human Development (SEHD), Dhaka, 1998.

[7] S. Parveen and N. Nakagoshi, "An analysis of pesticide use for rice pest management in Bangladesh", J. Int. Dev. Coop., 8, 2001, pp. 107-111.

[8] C. M. Meisner and S. Dasgupta, "Identifying Pesticide Hotspots: The Case of Bangladesh", Mimeo, 2004, Available at: http://www.worldbank/nipr (Accessed on 3th August 2016).
[9] Anonymous, “Annual report 1999-2000”, Entomology division: Bangladesh Agricultural Research Institute. Dhaka, 2000 .

[10] The Daily Prothomalo, Dhaka, July 20 \& 21, 2008.

[11] Daily Star, "Pesticides may also kill ignorant farmers", Jan 5, 2010, Available at: http://www.bd64.com/today1.php?id=9525 (Accessed on 13th August 2016).

[12] S. J. Miah, A. Hoque, A. Paul and A. Rahman, "Unsafe Use of Pesticide and Its Impact on Health of Farmers: A Case Study in Burichong Upazila Bangladesh”, IOSR Journal Of Environmental Science, Toxicology And Food Technology, 8 (1), 2014, PP 57-67.

[13] M. Kishi, N. Hirschhorn, M. Qjajadisastra, L. N. Satterlee, S. Strowman and R. Dilts, "Relationship of pesticide spraying to signs and symptoms in Indonesian farmers", Scandinavian Journal of Work \& Environmental Health, 21,1995, pp. 124133.

[14] D. Pimental, H. Acquay and M. Biltonen, "Environmental and economic costs of pesticide use", Bioscience, 42, 1992, pp. 750-60.

[15] L. Rosenstock, M. Keifer, W. E. Daniell, R. McConnell and K. Claypoole, "Chronic central nervous system effects of acute organophosphate pesticide intoxication", Lancet, 338, 1991, pp. 223-227.

[16] Bangladesh Population Census, Bangladesh Bureau of Statistics; Cultural survey report of kaligonj and Jhenidah Sadar Upazila, 2007. 